\title{
'Bus fare, please': The economics of sex and gifts among adolescents in urban South Africa
}

Carol E. Kaufman

Stavros E. Stavrou

Follow this and additional works at: https://knowledgecommons.popcouncil.org/departments_sbsr-pgy

Part of the Demography, Population, and Ecology Commons, Domestic and Intimate Partner Violence Commons, Family, Life Course, and Society Commons, and the International Public Health Commons How does access to this work benefit you? Let us know!

\section{Recommended Citation}

Kaufman, Carol E. and Stavros E. Stavrou. 2002. "'Bus fare, please': The economics of sex and gifts among adolescents in urban South Africa," Policy Research Division Working Paper no. 166. New York: Population Council. 
"Bus Fare, Please":

$>$

$\mapsto$

The Economics of Sex

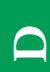
and Gifts Among Adolescents in Urban South Africa

Carol E. Kaufman Stavros E. Stavrou

$\varangle$

되

2002 No. 166

$\infty$

다기

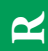

$\succ$

0

$\mapsto$

$\mapsto$

0

$5 \bigcirc \underset{19}{Y}$ E A R R S

$A$ 


\title{
"Bus Fare, Please": The Economics of Sex and Gifts Among Adolescents in Urban South Africa
}

\author{
Carol E. Kaufman \\ Stavros E. Stavrou
}

Carol E. Kaufman is currently Project Director at the University of Colorado Health Sciences Center, American Indian and Alaska Native Programs, Denver, Colorado. She was a Research Associate at the Population Council at the time of fieldwork. Stavros E. Stavrou is Researcher at the Irish Centre for Migration Studies, Cork, Ireland, and formerly the Managing Partner at DRA-Development, Durban, South Africa. This research was made possible by the generous support of DRA-Development Research Fund, the Rockefeller Foundation, USAID Cooperative Agreement No. CCP-A-00-94-00013-04 with the Policy Research Division at the Population Council entitled "Program for Understanding and Meeting the Needs of Adolescents." 


\begin{abstract}
Force or coercion are often a part of sexual relationships in South Africa, especially among adolescents. This coercion is also often pinioned by an economic exchange: gifts or favours for sex. Studies have pointed out the negative consequences of the exchanges which are often characterised by large age differences ("sugar daddies') or power imbalances. Perhaps more pervasive but largely ignored, gift-giving in same-age relationships also may be associated with sexual leverage, an exchange which somehow entitles one partner physical and sexual rights to the other's body. The circumstances surrounding gifts and favours may shape young women's and men's sexual experiences, their ability to negotiate the circumstances of those encounters, and the possibility of concluding or remoulding a relationship into another form. Using focus group discussions collected in the Durban metropolitan area between September and December of 1999 among adolescents age 14-22, we examine the economic context of gift giving or receiving and its relationship to patterns of risky sexual behaviour such as unsafe sex practices, and reports of sexual coercion or force. We find that gift-giving among same-age adolescents is common and important to shaping sexual relationships. Adolescents associate money or cash with prostitution, but do not consider gifts as such. Types of gifts and their meaning varied considerably by racial group and by gender.
\end{abstract}

This material may not be reproduced without written permission from the authors. For a list of Policy Research Division Working Papers, including those available for downloading in PDF format, see www.popcouncil.org/publications/wp/prd/rdwplist.html. 
Coercion is often a part of sexual relationships in South Africa, especially among adolescents (Luke 2001; Wood et al. 1998b; Wood and Jewkes 1997; Varga and Makubalo 1996; Varga 1997). Less frequently documented, though probably more pervasive, is the fact that sexual relationships are also often pinioned by an economic exchange: gifts or favors for sex. Studies in other settings have pointed out the negative consequences of these exchanges that are often characterized by large age differences or power imbalances, as when teachers trade good grades for sex with their students (Heise, Moore, and Toubia 1995; Mensch and Lloyd 1998). These types of gifts-for-sex exchanges have received research attention because of their inherently exploitative nature. However, gift giving of any kind within a relationship — or to establish a relationship — can also be associated with sexual leverage, an exchange that somehow entitles one partner to physical and sexual rights to the other's body. Simple gifts exchanged between an adolescent boy and a girl of the same age may also influence the pace and progress of that relationship. In short, the circumstances surrounding gifts and favors may shape young women's and men's sexual experiences, their ability to negotiate the circumstances of those encounters, and the possibility of ending a relationship or remolding it into another form. Gift giving often sets the parameters of sexual experiences for adolescents, with serious implications for pregnancy and the transmission of HIV and other sexually transmitted infections. In South Africa, where adolescent parenthood is widespread and the prevalence of HIV daunting, gifts may have life-altering —or life-threatening-implications. Yet, the everyday nature of gift giving, its widespread practice, and the fact that it can be undertaken for reasons other than sexual ones, for example altruism or trust, have camouflaged its importance: we know little about gifts and the role they might play in the lives of adolescents.

The present study explores the economic context of gift giving or receiving and its relationship to patterns of sexual behavior including unsafe sex practices, imbalances of sexual power, and perceptions of coercion. This paper also addresses the everyday nature of gift giving and dating experiences. That is, gift giving is understood by many to be a natural part of a relationship that may or may not result in coercion or a loss of negotiating power; we seek to understand the points at which gift giving may lead to risky behavior. The paper has three parts. The first reviews the literature on the content and form of adolescent relationships with a view to better understanding the role of gifts 
and the types of sexual relationships they might bring about. Using data collected in Durban, South Africa, we then describe the expectations adolescents have about sex in a relationship and the role of gifts in the nature and progress of those relationships. We then turn to the connections between risky sexual behaviors, reports of sexual coercion, and gift giving. Are girls or boys who accept gifts likely to engage in risky sexual activity? Does accepting a gift diminish one's ability to request use of condoms? Under what circumstances do gifts and violence in relationships go hand in hand? Do these circumstances differ for boys and girls? Or by race or ethnic group? Finally, the paper concludes with implications for programs and policies related to adolescent sexual behavior and to reproductive health and decisionmaking.

\section{CONCEPTUALIZING GIFTS IN RELATIONSHIPS: COERCION, ACQUiescence, AND STRATEGY}

A review of the literature on gifts uncovers a growing body of research on coercion, especially in adolescent relationships (Luke 2001; MacPhail and Campbell 2001; Silberschmidt and Rasch 2001; Heise et al. 1995; Heise et al. 1994; Ulin 1992). We argue, however, that casting gifts as solely facilitating coercion in sexual relationships undermines an understanding of more subtle — and perhaps more pervasive—forms of manipulation by both parties. We argue that a broader understanding of what gifts are, and how they are perceived by those in a relationship, is necessary to understand their effect on sexual relationships and the consequences for sexual health. We first consider the conditions of sex and communication around sex for adolescents, including coercion. Because of the limited attention to gifts in the context of adolescent relationships, we consider frameworks or approaches used in studies on coercion. These serve as a background against which to consider how gift giving among adolescents is similar to or different from coercion.

Adolescence is often a period marked by scant economic resources, high demand for material goods, and high levels of peer influence and pressure. In many sub-Saharan African countries, especially in the southern region, adolescence and young adulthood is also the age group in which HIV infection is spreading the most rapidly (U.S. Census Bureau 1999). A growing body of research has explored the relationships between coer- 
cion, sex, and possible outcomes such as disease transmission or unwanted pregnancy among adolescents. These studies tend to take coercion (and violence) or the threat of it as the point of departure for their research questions, and with good reason. Educational campaigns and reproductive health choices in contraception are useless if young men and women feel that sex on their partners' terms is the only alternative to violence. Wood and Jewkes (1997), for example, found in their discussions with black teenage girls in a South African township ${ }^{1}$ that few were in relationships that did not involve physical violence. In fact, coercion and violence were so common that many of these young women understood it as an expression of love. The researchers found that sex among adolescents often involved very little negotiation or communication. Condom use is a particularly difficult topic among youth since it connotes unfaithfulness and uncleanliness, and many girls reported a fear of retribution for initiating a conversation on the topic (Varga and Makabulo 1996; Varga 1997). In these studies, the focus is physical force and its relationship to power and sex. Often underpinning the power dynamics in relationships, whether or not they are violent ones, is gift giving. Few researchers have considered how economic exchange or gifts may influence adolescents' sense of self-efficacy or power. In many settings, especially in sub-Saharan Africa, even small gifts may hold economic value too attractive to decline. Gifts coupled with fierce social pressure to have a boyfriend or girlfriend and be sexually active may prove to be a disconcerting duo. If a girl accepts a gift from her partner, does this mean she has accepted the relationship as a sexual one? Or that she has abdicated her rights to negotiate the terms of the sexual relationship?

Many studies exploring coercion or force in relationships have sought to situate the relationships within the context of power imbalances and large age differentials, and in this way have touched on the role of gifts. Relationships with older men ("sugar daddies") and teachers are perhaps the power-imbalanced attachments most frequently considered. In the former case, wealthier older men, often "family" men who are married and have children, give money, transport, or other gifts to young women as an explicit part of a sexual relationship. While few condone these types of relationships, research has suggested that girls and sometimes boys pursue them as a "rite of passage" (Dinan 1983), or as a means to economic survival, security, and/or maturity (Meekers and Calvès 
1997; Kaufman et al. 2001; Silberschmidt and Rasch 2001). Sexual liaisons between teachers and students are another type of power-imbalanced relationship that has received greater attention in recent years. Mensch and Lloyd (1998), for example, describe a climate found in many of the Kenyan schools in their sample as being hostile to girls in part because of teacher harassment of students. Quite often that harassment takes the form of a sexual relationship in exchange for passing marks or help with homework; in the worst instances, sex with students occurs because of threats of a failing grade. Of note is that both boys and girls have been subject to this form of harassment in schools.

A few studies have gone beyond sugar daddy or teacher-student relationships to consider economic exchanges more broadly. Meekers and Calvès (1997) report that for their study participants in Cameroon, economic support was a major reason for premarital sex among girls, but also among some boys (who were seeing "sugar mummies"). Confirming the work of Bassett and Mhloyi on Zimbabwe (1991), many young adults in the Cameroon study have no means to support themselves except through gifts from boyfriends or girlfriends. Boys and less often girls seek multiple partners as a strategy for increasing the resources available to them if they need money or other goods. Meekers and Calvès conclude that economic hardship may increase the number of sexual partners for both boys and girls, thus also increasing their risk for HIV. Nnko and Pool (1997) also find that money and rewards are extremely important in sexual relationships among adolescents in Tanzania, and indeed that sex does not occur without economic exchange in some form. They assert that both boys and girls are well aware of these dynamics and are adept at seeing through deception and negotiating good exchanges. In short, they assert that force is an ambiguous concept in the face of the economic valuation of any relationship. In these studies, girls (and sometimes boys) report that they prefer partners who are economically able to support them. However, the studies fall short of assessing the meaning of gift giving within relationships and the implications for negotiating sex itself. Importantly, while a relationship with an economically stable partner often implies a large age gap — and it is these relationships that receive the most attention in examining power differentials and potential for abuse-all studies reviewed here note that gift exchange occurs widely in same-age adolescent relationships as well. Implications for gift giving are not restricted to sugar daddy relationships. 


\section{The ReSEARCH CONTEXT AND METHOdOLOGY}

South Africa has both a high level of teenage pregnancy (about 32 percent of 19year-olds have given birth at least once) and an extremely high level of HIV infection among teenagers (21 percent among 15-19-year-olds in 1999). Family planning services, while not necessarily adolescent friendly (Wood et al. 1998a; Mfono 1998), are extensive in the country, and condoms and contraceptives generally are widely available for those who wish to use them. Past events in South Africa have set the stage for exceptionally high levels of violence throughout society, especially violence and coercion against women, and a recent study estimates that about one in four women have been physically assaulted by their partners or former partners at least once (Jewkes et al. 1999). ${ }^{2}$ While this level of violence against women may or may not be related to gifts, it is likely to set a background tone for the expectations associated with gift giving.

Durban is located on the east coast of South Africa in the province of KwaZuluNatal. The urban geography of Durban has widespread implications for the social makeup of the city and for community organization. The history of town planning in Durban is one of large-scale intervention by the authorities to create a racially segregated and industrially efficient space. Through the post-World War II period, policies of segregation that had existed before apartheid were reinforced and entrenched. Durban became a racially zoned city in which the four officially sanctioned race groups were forcibly placed in separate communities. Today residential areas are still primarily separated along race and class lines. Africans, who comprise about 60 percent of the Durban metro population and are predominately Zulu-speakers, live primarily in townships. The largest of the townships are located at the perimeter of the city, although a few smaller ones are dispersed within city boundaries. Africans are now also moving into inner-city areas and adjoining neighborhoods previously unavailable to them, and in many locations this has coincided with a movement of whites and sometimes Indians from city neighborhoods to outlying suburbs. For adolescents, this implies that the separate cultures of behavior that were the rule in the past continue to prevail, even though young men and women now have greater opportunity to mix socially and economically.

The key question we consider in this study is the impact of gifts on sexual relationships among adolescents in Durban. We explore these dynamics among boys and 
girls across the three dominant race groups in the region: African, Asian, and white. ${ }^{3}$ The cross-racial approach makes this study unique: most work in South Africa on adolescents has thus far focused primarily on African adolescents. While Africans constitute the majority, youth from other groups are also at risk of early pregnancy and HIV/ STI transmission, yet we know virtually nothing about their sexual attitudes or behaviors, how they might be similar to or different from those of blacks, or the implications of this diversity for programs and services.

This study draws on evidence from ten focus groups held in November and December 1999 in Durban. ${ }^{4}$ Averaging seven participants each, the focus groups were conducted along gender, racial, and residential lines. Stratified by key geographic areas (township, inner city, or suburban), neighborhoods were randomly selected as recruitment areas for the study. Fieldworkers familiar with those areas recruited participants according to appropriate age and sex groupings. No attempt was made to ensure homogeneity by education; although the majority of participants within each group were enrolled in some form of educational program, at least one or two were not attending school (with the exception of one group of young township girls, who were all attending school). Participants from inner-city neighborhoods were included as a separate geographic region since youth from these areas are more likely to mix with other racial groups and the social and economic dynamics of these neighborhoods are distinct from those of township areas. All focus groups were conducted in the respondents' language of choice and the proceedings subsequently translated into English. All focus groups were tape recorded; in addition, "notetakers" took written notes and in other ways assisted the moderators. ${ }^{5}$

In addition, a number of in-depth individual interviews were conducted with local community youth leaders and adolescents. These interviews preceded the focus groups and were intended to familiarize the researchers with "current trends" among adolescents. These included current slang and jargon, popular places to "hang out," regular leisure and sports activities, common drugs used, inter- and intraracial dynamics, different phases within intimate relationships, and popular definitions of various sex acts.

Respondents ranged in age from 14 to 22 , with just over one-tenth being single or not in a steady relationship at the time of the research. Of those who claimed not to be in 
a relationship, white participants constituted the majority, followed by Asians. By comparison, all African respondents indicated they were in a relationship, suggesting that African participants placed a high value on being seen to having one. Monogamy was the dominant partnership status for all participants in relationships, with all whites and female Africans and Asians currently in relationships claiming to have only one partner. One-fifth of African males and one-quarter of Asian males stated they had more than one partner at the time of the discussions. Eighteen- and 19-year-olds constituted over one-half of all participants who claimed to have multiple partners, suggesting that this age bracket may be particularly prone to promiscuity. Across all races men were more likely than women to report themselves to be in multiple-partner relationships, and also more likely report themselves to be single.

In this paper we argue that gifts are an important part of relationships in South Africa and contribute to the defining character of a relationship. The type of relationship in turn will determine expectations about sex and the risks adolescents will take, including use or nonuse of condoms or pursuing multiple partners. To examine these issues, the moderators' guided discussions began with the onset of relationships, the circumstances under which they became sexual, and the preferred timing of sex within them. Participants were then asked about the role of gifts and finally about the effect of gifts on sexual communication and coercion. The findings of the discussions are generally presented by age and race groups to maximize cross-group comparisons.

Any research that deals with the subject of sex must consider the honesty and completeness of participants' replies. Researchers in other settings have noted a tendency of adolescent participants in particular to over- or understate their experiences. It is impossible to gauge the level of honesty and accuracy with absolute confidence. However, with the exception of two focus groups - those with younger Africans who tended to be shy and reserved-participants were generally talkative and volunteered more information than was directly asked for. Conversations flowed easily between the moderators and participants as well as among respondents themselves. Indeed in many instances, focus groups planned for 90 minutes took well over two hours, an indicator of involvement beyond that initially expected. 


\section{SEX AND THE RELATIONSHIP}

Initiation of sex within a new relationship varied considerably across and within groups, ranging from the first date to six months later. Peer pressure played an important role in timing, a role that seems to carry two conflicting messages. First, premarital sex was discussed as though it were a given; sex before marriage was expected and accepted among these respondents. ${ }^{6}$ On the other hand, almost universally, boys and girls talked about the timing of sex in terms of upholding their reputation. Guarding one's reputation is perhaps not a new sentiment among youth in many settings. Alarming, however, was an acknowledgment that use of drugs and alcohol was pervasive and of course altered timing of sex. Participants unanimously agreed that the use of alcohol and drugs often acted as a catalyst for sex "before girls were really ready." Indeed, many of the girls felt they were often "too weak" to refuse the offer of particular designer drugs that were usually too expensive to purchase on a regular basis. White females admitted to "often" having sex in exchange for drugs, but that it was a "weekend thing" and usually only at "rave" parties.

White girls were especially conscious of negative labels used for girls who are accused of sleeping with too many guys: "this definitely propels us into the slut category," while the guys were described as "studs." Both labels were found to be pejorative. White boys expressed their interest in having sex as quickly and as often as possible, but felt that those girls who succumbed to their "charm" or "drugs" were either "loose" or "horny." Boys argued that "loose girls" were acceptable and a necessary component of any social circle, but that they could not be trusted because they were more likely to be disease carriers. Interestingly, however, the young men indicated that they did not alter their low frequency of condom use when having sex with "loose girls."

Inner-city African females attached the label of "cheap" to themselves should they have sex early into a liaison or with too many men. They expressed the need to trust and feel comfortable with men with whom they would consider having sex. Initiation of sex differed according to the familiarity of partners. If the man was from outside their circle, girls were more likely to sleep with him after about three or four meetings; but if he was from within, then "months had to pass" before engaging in sex. For example, this group of participants stated that they were more likely to have sex with a white guy 
earlier in a relationship than with an African, as the likelihood of the encounter "getting around" was virtually nonexistent. One respondent who had had a previous relationship with an Asian male was so disgusted with his lack of discretion that she vowed never to have a liaison with an Asian again.

In contrast, younger African girls, those under the age of 16, were more likely to have sex initially with a distant relative or a sibling of a close friend, rather than a stranger from outside their circle. Distant relatives were described as blood-related cousins or someone who came from the same clan. The discussions did not reveal any cases of incest, although some of the African respondents, both male and female, pointed to problems that younger girls in rural areas face with older uncles or cousins, particularly in instances where their fathers are migrant workers. They claimed that for many young girls, their first experience is a "forced one." Although they were "sure" that such happenings also occurred in urban society, it was less likely because of the greater exposure that girls have to both peers and family and because discussions on sex are not restricted as in rural areas.

African boys expressed a preference for early sex within those relationships that were casual or unlikely to lead to marriage. Unless you "wanted to marry the chick," two dates was sufficient waiting time. If the woman did not succumb to sexual demands at that point, then future dates would be unlikely. However, familiarity also played a role in these expectations. African males asserted that if the girl came from a family that was friendly with their own, then she was a sister and had to be treated with the same respect.

Asian girls argued that sex before marriage was culturally unacceptable; however, they also did not like the idea of being married as virgins, thus missing out on some of the "other spices" in life. ${ }^{7}$ Courtship that ended in sex had to be at least one dozen dates or three months long, although this period was shortened if the date was a white male. No female Asian respondents felt they would like to have a relationship with a black man, although they argued that some of the African American celebrities would be a highly desirable "catch." These girls felt that white as opposed to Asian men were less likely to "gossip" and thus their perceived "virtues" were safer. However, potential marriage with white men, for both cultural and religious reasons, was a limited option, hence it was inevitable that most Asian girls felt they would marry Asian men. 
Asian boys felt that to sleep with a girl before having at least ten dates meant that she was "loose" and not worth even introducing to their mates. They felt that white girls were easier to have sex with, and that generally Asian females held out longer and had sex only after "promises of some sort of future." On the other hand, they argued that Asian girls were more tolerant of affairs than white girls, who insisted on monogamy. Given that "these were the best years of our lives," such options limited boys' ability to "move around." Hence, they would rather not have a steady girlfriend and "play the field," rather than have a steady relationship and be limited to just one girl, even if sex were part of the relationship.

In short, all participants expressed an interest in sexual experimentation before marriage, even while the parameters of acceptability of "experimentation" varied considerably across groups. Part of playing the field or of courtship is giving gifts, and those gifts - as already noted with respect to alcohol and drugs - may considerably condition the expectations of sex.

\section{GIFTS AND GIFT GIVING}

The concept of what constituted a gift varied among participants. In general, flowers, chocolates, jewelry, clothes, lingerie, flowers, CDs, drugs, meals in a restaurant, drinks at a club, tickets to concerts, entrance fees to clubs, vacations, accommodation, and books were the most frequently mentioned items. African women between ages 18 and 22 years in the township maintained that if a woman comes from a poor family, offerings of food for the family home would be an acceptable gift. Not all gift giving was understood in material terms. Young African males from the township aged 14-15 years spoke about sex itself as being a gift, referring to it as something that is always there and did not need to be purchased.

Asians girls mentioned boyfriends' giving household accessories to their mothers and buying alcohol or tickets to sporting events for their fathers as common gifts. The giving and receiving of sweets, cakes, and other foodstuffs outside cultural occasions were also considered gifts. Asian males concurred and felt that it was a very "decent" way of gift giving because it did not put undue pressure on the girl. However, they argued that if the girl was considered a good "bet" for procuring quick sex, then the 
giving of "provocative" gifts such as lingerie and perfumes would be an appropriate strategy.

The giving of esoteric "things" was a form of gift giving among some whites, and natural objects such as sticks and stones were included on their lists. Acts of lavishness did not necessarily result in sex being offered in return, but created a degree of "closeness" that "inevitably" resulted in sex. A current trend in gift giving included designing and paying for tattoos and various forms of body-piercing jewelry both by men and women. Reciprocating with sex is part of such gift giving rituals; participants argued that the intention of such gifts was to provoke a sexual response from a partner.

African males did not explicitly cite "dates" as a gift, but insisted that taking girls out on a date was expensive and the right of something in return was taken "as given." If the girl insisted on paying, the expectations changed, however. If she was from a rich family, most boys stated that having the girl pay was perfectly acceptable, even expected. Sex then would be a prolonged negotiated process that took place on her terms. Meanwhile, if she was an ordinary "township girl" and still insisted on paying, then she was likely to be "some sort of feminist" and by implication "troublesome." In this instance it was best to weigh the odds before "committing your time" to the girl.

What clearly emerged was that monetary exchanges were not considered part of gift giving, either at the initiation of or during the early part of a relationship. Overwhelmingly, focus group participants argued that giving and receiving money during a relationship was viewed as a form of "prostitution" and thus not an acceptable part of any relationship. When asked what the expectations might be should money be given and received by partners early in a relationship, female participants claimed that this would mean the right to demand sex. Male participants said they would not offer money to a girl they were dating, as this would lower their opinion of her and that giving money to women was only for the purpose of having sex with her. Further, young men argued that payment of money to girlfriends may call into question their own masculine charms, for "if a girl will not sleep with me because of my charm, looks, and personality, then there might be something wrong with me." The notion of introducing the giving and receiving of money in a relationship belittled the notion of the "chase" and of "wooing," and as such removed an important element from the early part of the relationship. 
The giving of money as a gift during the "mature" part of any relationship, however, was appropriate if the circumstance warranted it. Money exchanges for the purpose of buying a birthday or "anniversary" gift if the partner had no time to undertake the purchase were perfectly acceptable. Money given for the purpose of purchasing lingerie, underwear, and other personal items of clothing, in cases where the partner was "too embarrassed" to make the purchase, was also acceptable. Among Asian and African respondents, giving money to a partner when at a "casino" or at the "races" for gaming purposes was also seen as perfectly in order. Indeed, female respondents argued that if "gambling money" were not offered to them, they would feel they have been insulted by their partner. African and Asian male respondents accepted that this was part of the norm, and they did not consider the giving of money as a gift, but rather as an obligation to their partner for accompanying them to such a place.

A number of African participants claimed that money in the form of a gift given for the purpose of paying for education or the purchase of educational materials was perfectly acceptable. A number of participants reported they had accepted money from men for these purposes, but they added that they felt the pressure to return the "favor" by having sex. Such a form of gift giving among white and Asian participants was considered to be a "no, no," as the person giving the money would have some form of right over the person accepting it.

The giving and accepting of university lodging at an on-campus residence was said to be a prevalent form of gift giving and receiving among "out-of-town" students at universities and technikons. Essentially female students would accept free lodging at campus residences from older male students (and in some cases from lecturers or dormitory supervisors) in return for being in a "resident relationship" with the man. Sex was an integral component of that relationship. Respondents also claimed there were cases of female students who went through a three-year degree or diploma program by embarking on such "resident relationships" for the sake of ensuring on-campus accommodation. A rough calculation of various case studies revealed that, on average, female students who embarked on such activities changed "resident relationships" once a semester. Thus it was perfectly normal for a student completing a three-year degree or diploma program within the specified time period to have "at least one dozen resident relationships." Participants 
also claimed that male students had lists of these girls and that an informal "transfer system" operated among men, who would "swap" sex partners at informal trading sessions.

Both African male and female respondents also argued that there were particular "types of girls" of their age group who shared male partners among them. Here the inverse relationship occurs, where girls either "trade" or "lend" boyfriends depending on what they themselves sought at a given moment. Depending on the wealth or status of the men in question, they were labeled accordingly. A man with a good car who did not mind using it to provide transportation was a "Minister of Transport," whose primary task would be to drive the girl to places she would like to visit. Given the nature of settlement patterns in South Africa, it was not uncommon for a girl to trade sex with a man if he was prepared to take her to visit relatives in distant towns or rural areas. Such sex did not occur at the point of visit but only on the safe return back home. A "Minister of Finance" is a provider of "pocket money" for the intention of purchasing clothing or perfume. A "Minister of Education" is a man who pays fees, purchases books, or provides accommodation at a residence. Such "ministers" tend to proliferate during the middle of the academic year and just before graduation, which can only take place if the student has settled her account with the institution she has attended. "Ministers of Foreign Affairs and Tourism" are usually in high demand during the long vacation periods, but may also be sought out whenever women seek a change of scenery. Exchange of sex for such "favors" is seen as being quite common and is not restricted to a particular age or socioeconomic group, although respondents argued that when women married, the various "ministers" fall out of their lives. Throughout this entire period there is the "Straight Minister," the one man who is regarded as the lover of her life and who does not have to exchange favors or money for her company. Many of the African men accepted the situation and did not consider themselves as being "used." As long as they have sexual intercourse with that "girlfriend," the relationship is not complicated by some ritual of courtship that is often deemed as being more expensive.

Gifts are a part of relationships according to the discussions in these focus groups. While monetary gifts are berated as degrading and demeaning — as prostitution—other types of gifts quite often are a means to the same end. Gifts are often selected and accepted implicitly and sometimes explicitly as a symbol of imminent sex. They con- 
note physical obligation. In the next section we explore whether all gifts connote the same kind of obligation, and how males and females handle that obligation.

\section{GIFTS AND SEX}

According to most male and female participants, physical obligations such as kissing, petting, and oral sex were exchanged for gifts as signs of appreciation. The "worth" of the gift often determined the type of "sex" that was given. Kissing among Africans and whites of both sexes was seen as an act of intimacy, but also could be exchanged for a drink or "soft" drugs. Indeed, this was "what you do with your cousins" and by implication could not really be described as part of the sexual repertoire. Asian women, however, argued that kissing was an integral part of the sexual ritual and without it the "rest could not follow." Certainly, the exchange of a kiss for a gift was a response that was carefully considered. Petting or heavy petting was not considered as being of any importance among Africans and whites, but was seen as a very intimate act among Asians. For Asians such acts were a precursor to "full sex" and had to be carefully planned in order that the latter does not happen out of sequence. White and African girls felt that heavy petting in exchange for gift giving in the form of entertainment and/ or drinks and drugs was "par for the course." Indeed, they felt that they "scored" twice, having received a gift and sexual satisfaction, while the men had to pay for the entertainment without receiving any sexual gratification. Men, on the other hand, felt they had reached some sort of "goal" and in the process laid "claim" to the girl in question. For men, this was an important stepping stone toward the final conquest.

Africans and Asians of both sexes argued that oral sex played little part in their sexual rituals and as such had nothing to do with giving and receiving gifts. White participants in contrast felt that oral sex was integral in their "relationship building." Depending on the value of the gift or to a lesser extent the ambience of the situation, white women may show their gratitude with oral sex. Almost all focus group participants agreed that when large and costly gifts were given or expected, such as gold jewelry and "overseas trips," full penetrative sex was given and accepted.

The ritual of gift giving and receiving among participants was an important component to creating and maintaining relationships, although both the need to offer gifts 
and the value of the gift itself declined as the relationships matured. However, during the early stages, partners who did not give gifts were likely to find themselves rejected. "Going dutch," although a common practice among friends, had no role to play in the "first one or two" dates where one person invites the other out. Discussions about girls and their gift giving revealed that girls do give gifts such as aftershave, CDs, and sometimes sex to males as a sign of their commitment and appreciation of the relationship or to maintain or sustain levels of affection. All but two groups (township males aged 1415 years and white males) were adamant that such gifts were not given in exchange for sexual favors. African and Asian men were less likely to accept being invited out by a girl and then letting her pay all the expenses. They argued that it stripped them of part of their masculinity, and they felt that should sex follow "a night out" they had to "perform at a higher level than usual." A minority of participants argued that this undue pressure often had negative effects, including the "inability" to have an erection or the experience of a premature ejaculation. Other participants would query the "real motives" of the girl if she wanted to pay, stating that there had to be "a catch somewhere." White men and women were more relaxed about having women pay for a date, and men did not see it as a threat to their libido or as worth "thinking about."

Although the overwhelming number of participants included themselves in the profile of gift giver and receiver, they would not have considered themselves as a "regular" in this field. Indeed, particular profiles of both gift givers and receivers existed and these were not necessarily flattering. On the one hand they included girls who were "gold diggers" or "cheap whores" or on the other hand poor girls who simply needed to "get by." Students who involved themselves in resident relationships tended to fall into the latter category. Men who give gifts were described by both sexes as being "losers," "rude boys," "scummy guys," "playboys," "drifters," or "rich."

Gifts are linked not only to sex, but to the type of sexual activities in which couples engage. In other words, evidence from the focus groups suggests that gift giving among adolescents leads one to a particular sexual path. Two vital links between gifts and types of sexual activities are expectations or preferences and communication. How do gifts influence the negotiation process? And importantly, in the midst of an AIDS epidemic, do gifts facilitate or dampen discussion about condom use? 


\section{CONDOM USE AND GIFT GIVING}

Many African female respondents maintained that it was neither usual nor easy to discuss sex and sexual issues. Girls worried that if they did discuss sexual issues with their partners they would be misjudged. As a result sexual matters may be discussed with close same-sex friends. White males on the other hand maintained that they all spoke openly with their partners about sex, abortion, and contraception. They did not, however, talk about AIDS because this topic was seen as being too serious. A few respondents, particularly younger Africans and Asian girls, maintained that talking about sexual desires or preferences did occur, but that it was possible only in relationships that had been ongoing for a long time.

The responses regarding condom use were alarming in light of the ever-growing HIV/AIDS epidemic in South Africa today. Respondents were asked what would happen if a girl is given a gift but she wants her partner to wear a condom and he refuses. White men were the most flippant in their outlook toward condom use and generally insisted that regardless of whether or not a gift was given, they would not have sex with girls who insisted they use a condom if they did not feel like doing so. If white males gave a gift and sex was to follow, they certainly would not expect girls to demand the use of a condom, with some men resorting to the "necessity of force" if that was required. "Force" was defined as persuasion, ranging from gentle chiding to outright threats. Although male participants argued that they themselves would not resort to physical force, they were quick to point out that they knew "many losers" who do.

Further discussions revealed that some white males had perhaps "intimidated" girls into sex without a condom, "but would never have 'date raped' anyone." Also pertinent was the fact that most of the group acknowledged "making promises" to girls before sex that they would not keep, particularly if they did not want to use a condom. The white female group argued that boys largely preferred not to use condoms, but when "push came to shove, all they want to do is finally get it in," so they would succumb to the demand to use condoms. They argued that for the first two or three "sex sessions" condom use was mandatory, but after that girls would drop their demands. Interestingly, none of the women would resort to asking for an AIDS test before beginning a sexual relationship. White women argued that although they encountered experi- 
ences of "strong persuasion," they themselves had never been physically threatened. Cases of "date rape" were encountered, but not necessarily linked to gift giving. White females strongly argued that they would not be persuaded to forgo the use of condoms at the outset of a sexual relationship if a gift was offered.

African females felt that if they "wanted" to see the man again, then the issue of condoms "becomes a nonissue and you take your chances." But, unless they "really knew the guy," they would insist on the use of condoms. Respondents argued that men often got argumentative about the use of condoms and sometimes ended up "slapping the woman around." Indeed, men felt that if a girl accepted a gift just before lovemaking or agreed to a gift afterward, then she was denying herself the right to ask a man to use a condom. Men also claimed that girls who come from "rural areas" are less sophisticated and were easily seduced "even by worthless gifts," allowing themselves to be completely manipulated. Others stated that some women who want to "catch a guy" would pretend to agree not to use a condom, especially after being offered a gift of sorts, but that in reality she manipulated the situation in order to become pregnant.

African males, like their white counterparts, argued that condom use was restrictive and that they would prefer to have sex without one, but in this day and age they could not take chances with someone they did not know. After a few "sessions," however, they would "expect" the woman to agree with them and drop the demand to use condoms. If the woman did not consent, they would not date her again. None of the men felt they would use gift giving as a means of encouraging a woman to drop her demands to use a condom. But they did argue that if they had spent a lot of money "entertaining" the woman, then they would be aggrieved if she did not consent to sex. African male respondents were quick to argue that older men, particularly those "from out of town," sought out young women (described as 15-16-year-olds) to have sex without the use of condoms. These men would offer gifts, usually clothing, shoes, perfume, or money. Younger African girls agreed that this was one of the major reasons for not wanting to have sex with older men; however, if they were to be offered a large "bus fare," then they might consent to their male partner's not using a condom.

Asian participants of both sexes argued that the use of condoms was important, not necessarily because of AIDS but in order to avoid unwanted pregnancies. Asian 
women would not be dissuaded by an expensive gift from asking her partner to use a condom, while Asian men argued that they would be "mad" to have to engage in sex with anybody without condoms. Respondents argued that across most Asian communities, "getting a stuckie [girl] pregnant means forced marriage"; thus, unless a man knew a girl was using contraception, he would not suggest sex without a condom. Indeed, it was said that "some girls, especially the grotty [ugly] or older ones," would sleep with a man without a condom just to "catch the ouk [chap]."

Among the younger age groups, the use of condoms was seen as being almost imperative and the issue of gift giving would not sway girls' opinion. Risk aversion ranked highest among Asian participants and lowest among Africans, although each of the three groups saw risk aversion differently: Asians in terms of "forced marriages," Africans in terms of AIDS, and whites in terms of all the "hassles."

Apart from those Asian males who viewed condoms as a necessary means of birth control, the discussions about condom use revealed a frightful level of ignorance, denial, and, often for females, a sense of helplessness or defeat. The evidence suggests that gifts are likely to reduce the ability of girls to demand condom use. Males tend to portray themselves as not pressuring women to have sex without a condom, gifts or no gifts; yet the conversations revealed that they did not feel condom use should accompany sex, especially if they had spent a lot of money during the evening. Perhaps more disturbing is that in many cases, the expectation is that after just two or three sexual encounters, neither men nor women expect condom use. As noted above, sometimes this is because gifts are presumed to bestow sexual privilege, a privilege that is sometimes assumed forcibly.

\section{COERCION AND GIFTS}

Discussions of violence indicated that force and abuse were not uncommon in relationships. Females much more than males acknowledged a link to gifts; however, participants in general, with the exception of African females, tended to see gift giving and violence as independent. Participants were able to discuss cases of abuse, instances of violence, and strategies for handling abusive situations, but ties to gifts were not common. To the extent that violence between partners is arbitrary and an expression of power and control rather than a response to a particular action or event, this is not sur- 
prising. Indeed, the very loose connection between gifts and violence is in sharp contrast to the role of gifts in sexual communication, especially surrounding condom use. The effect of gifts on the course and development of a sexual relationship appears to be greatest in those relationships where violence is absent.

A detailed discussion of date rape ended with the agreement that rather than its becoming more frequent, girls were more aware of the topic and as such it was more likely than previously to emerge as an issue. The use of "rape drugs" was becoming "very common" among whites, particularly at raves. Described as a "tranquilizer for horses," such drugs have begun to permeate house parties and are now common among those under age 16. White males argued that although they know of men who beat up girlfriends, it was impossible to link this to gift giving, arguing that it was a symptom of male dominance.

African females maintained that gift giving for sexual favors is an insult and males sometimes become violent if they feel insulted. They maintained, however, that if communication is good, girls do not get beaten. African males admitted to sometimes becoming angry and forceful, if a girlfriend made them feel foolish. Generally, most men claimed that they would not "deliberately" set out to hit a woman, but admitted that it did happen and should not be condoned. Asian respondents dismissed this discussion by saying that although gender-related violence did occur, it was impossible to link it to gift giving, primarily because the giving of gifts was "common."

Researchers have increasingly considered the use of coercion within sexual relationships and the consequences for reproductive health. Our research does not take issue with the importance of understanding and addressing violence in relationships, but our emphasis was on gift giving. What we address here is a more subtle form of coercion or persuasion, yet one likely to be pervasive among adolescents.

\section{DISCUSSION}

As with any study, this one has its limitations. We spoke with relatively few individuals for a limited period of time, and our conclusions must be considered preliminary. Nevertheless, our evidence suggests that gifts play an important role in shaping the sexual terms of a relationship and may have pernicious effects on the ability of women-and sometimes of men-to express their preferences for the type of sexual activity, its initiation, or the use of safe practices when engaging in sex. Participants in 
our focus groups viewed gift giving as commonplace, a part of courtship and a means with which to establish relationships and intimacy. Excessive gift giving was viewed negatively, and most recognized that this occurred because of either economic necessity or misplaced values. While reticent to acknowledge the impact of gifts on their own sexual behavior and activities, most participants affirmed that gifts do play a role in negotiating sex and in altering expectations of sexual activity.

Clearly those adolescents who are economically disadvantaged are at greater risk of trading sexual favors - often unprotected ones-for money or other financial rewards. However, most adolescents are well aware of the symbolic meaning of gifts, and perhaps because gifts are so commonly used as means for achieving sexual goals, gift giving is also widely accepted and rarely questioned. One pragmatic implication is that questions on surveys asking about giving or receiving gifts for sex are unlikely to produce many affirmative answers among adolescents. When the relationship is stated in such direct terms, it is understood as prostitution and, for most people, is far removed from their own experience.

This analysis also indicates that oral sex is common among some adolescent groups. Often this is a strategy to avoid full penetrative sex and the possible disease transmission related to it. However, recent research indicates that oral sexual contact—with or without open sores or lacerations-is associated with a higher probability of HIV transmission than previously assumed (Graham 2000). While we did not explicitly explore whether our participants realized condoms were necessary when engaging in oral sex, the content of their discussions implied they did not. For this age group, more information on types of sexual activity and the possible health consequences may be life-saving.

Policies and programs regulating gift giving are obviously not feasible. Gifts have always been a part of relationships, and this is unlikely to change. The consequences of accepting gifts, on the other hand, are likely to have shifted considerably in recent years and now, in the midst of the AIDS epidemic, may have fatal outcomes. Programs concerned with safe sex practices should broaden their scope to include gifts as part of the context in which sexual decisions are taken. For example, in role-plays or other activities where communication skills are emphasized, communication must include a vocabulary not only about sex and safe practices, but also about expectations and the intentions symbolized in a gift. 


\section{NOTES}

1 A township is an urban settlement set aside for blacks and coloureds under the former apartheid regime. Often they are located some distance from formally white cities, but in Durban a few fall within the city boundaries. Townships are usually densely populated and are highly diverse economically, with housing ranging from squatter and shack settlements to veritable mansions.

2 This estimate is based on a representative sample of 1,304 women aged 18-49 from three provinces.

3 Under apartheid South Africans were officially assigned to one of four population groups: black or African, coloured (of mixed heritage), Indian or Asian, and white. While this official categorization of the population ended with the first democratic elections in 1994, the legacy of race-based policies continues and these categories still generally connote particular social and economic attributes, and often cultural distinctions. The coloured community, which constitutes almost 10 percent of all South Africans, makes up less than 2 percent of the population of the Durban metropolitan region and as such was omitted from this study.

4 The focus groups were an extension of a broader project on adolescents and their transitions into adult roles and responsibilities. That study included a major data collection component, carried out in September and October 1999. A representative sample of over 3,000 adolescents aged 14-22 in Durban and the neighboring district of Mtuzini were interviewed about their educational and work experiences as well as their sexual and reproductive knowledge, attitude, and behaviors. Future work on this topic will incorporate results from analysis of those data.

5 Many of the participants were uncomfortable about the fact that the focus group sessions were recorded, citing potential problems should parents or partners acquire the tapes. Unfortunately, under South African law, the only information that is deemed confidential for all purposes is that between solicitors and their clients. As such, no research information is exempt from a court subpoena. Thus, the tapes were subsequently destroyed after being transcribed. 
6 Interestingly, respondents lamented that younger girls, from the age of 14, were fairly "easy" when it came to sex, particularly with "older guys" aged 16 to 18 years old. Participants estimated that in the past five years the age of initiation of sex has "plummeted" from 16 to 13 years.

7 None of the Asian girls interviewed was Muslim or Gujarati. They came from Hindu, Tamil, or Christian families.

\section{REFERENCES}

Bassett, Mary T. and Marvellous Mhloyi. 1991. "Omen and AIDS in Zimbabwe: The making of an epidemic," International Journal of Health Services 21(1): 143156.

Dinan, C. 1983. "Sugar daddies and gold-diggers: The white-collar single women in Accra," in Christine Oppong (ed.), Female and Male in West Africa. London: George Allen and Unwin.

Graham, Barney. 2000. "The path to an AIDS vaccine: Choices and challenges," presentation given at the annual Rocky Mountain Regional Conference on HIV Disease, Denver, February 17.

Heise, Lori, Kirsten Moore, and Nahid Toubia. 1995. Sexual Coercion and Reproductive Health: A Focus on Research. New York: Population Council.

Heise, Lori, Jacqualine Pitanguy, and Adrienne Germain. 1994. Violence Against Women: The Hidden Health Burden. Washington DC: The World Bank.

Hof, Caroline and Annemiek Richters. 1999. "Exploring intersections between teenage pregnancy and gender violence: Lessons from Zimbabwe," African Journal of Reproductive Health 3(1): 51-65.

Jewkes, Rachel. 1999. Personal communication.

Jewkes, Rachel, Loveday Penn-Kekana, Jonathan Levin, Matsie Ratsaka, and Margaret Schrieber. 1999. “He Must Give me Money, He Mustn't Beat me” : Violence Against Women in Three South African Provinces. Pretoria: CERSA (Women's Health, South African Medical Research Council. 
Kaufman, Carol, Thea de Wet, and Jonathan Stadler. 2001. "Adolescent pregnancy and parenthood in South Africa," Studies in Family Planning 32(2): 147-160.

Lear, Dana. 1995. "Sexual communication in the age of AIDS: The construction of risk and trust among young adults," Social Science and Medicine 41(9): 13111323.

Luke, Nancy. 2001. "Cross-generational and transactional sexual relations in sub-Saharan Africa: A review of the evidence on prevalence and implications for negotiation of safe sexual practices for adolescent girls," Washington, DC: International Center for Research on Women, mimeo.

MacPhail, Catherine and Catherine Campbell. 2001. "II think condoms are good but, aai, I hate those things" ": Condom use among adolescents and young people in a South African township," Social Science and Medicine 52: 1613-1627.

Meekers, Dominique and Anne-Emmanuèle Calvès. 1997. “"Main' girlfriends, girlfriends, marriage, and money: The social context of HIV risk behavior in sub-Saharan Africa," Health Transition Review 7 (supplement): 361-375.

Mensch, Barbara and Cynthia B. Lloyd. 1998. "Gender differences in the schooling experiences of adolescents in low-income countries: The case of Kenya," Studies in Family Planning 29(2): 167-184.

Mfono, Zanele. 1998. "Teenage contraceptive needs in urban South Africa: A case study," International Family Planning Perspectives 24(4): 180-183.

Muehlenhard, C.L. and M.L. McCoy. "Double standard/double bind: The sexual double standard and women's communication about sex," Psychology of Women Quarterly 15: 447-456.

Nnko, Soori and Robert Pool. 1997. "Sexual discourse in the context of AIDS: Dominant themes on adolescent sexuality among primary school pupils in Magu district, Tanzania," Health Transition Review 7 (supplement): 85-90.

Richter, Linda. 1996. A Survey of Reproductive Health Issues among Urban Black Youth in South Africa. Pretoria: Society for Family Health. 
Silberschmidt, Margrithe and Vibreke Rasch. 2001. "Adolescent girls, illegal abortions and 'sugar daddies' in Dar es Salaam: Vulnerable victim and active social agents," Social Science and Medicine 52: 1815-1826.

Ulin, Priscilla R. 1992. "African women and AIDS: Negotiating behavioral change," Social Science and Medicine 34(1): 63-73.

U.S. Census Bureau. 1999. HIV/AIDS Surveillance Data Base. Population Division, International Programs Center.

Varga, Christine A. 1997. "Sexual decision-making and negotiation in the midst of AIDS: Youth in KwaZulu-Natal, South Africa," Health Transition Review 2 (supplement 3): 45-67.

Varga, Christine. 1999. "South African young people's sexual dynamics: Implications for behavioural responses to HIV/AIDS," in Resistances to Behavioural Change to Reduce HIV/AIDS in Predominantly Heterosexual Epidemics in Third World Countries, ed. by J.C. Caldwell et al. Canberra: Health Transition Centre, National Center for Epidemiology and Population Health, Australian National University.

Varga, C.A. and L. Makubalo. 1996. "Sexual (non) negotiation,” Agenda 28: 31-38.

Wood, Katharine and Rachel Jewkes. 1997. "Violence, rape, and sexual coercion: Everyday love in a South African township," Gender and Development 5(2): 41-46.

Wood, Katharine, Joyce Maepa, and Rachel Jewkes. 1998a. “Adolescent sex and contraceptive experiences: Perspectives of teenagers and clinic nurses in the Northern Province," mimeo.

Wood, Katharine, Fidelia Maforah, and Rachel Jewkes. 1998b. "'He forced me to love him': Putting violence on adolescent sexual health agendas," Social Science and Medicine 47(2): 233-242. 


\title{
POLICY RESEARCH DIVISION WORKING PAPERS
}

\author{
Recent Back Issues
}

133 Mary Arends-Kuenning and Sajeda Amin, "The effects of schooling incentive programs on household resource allocation in Bangladesh."

134 John Bongaarts and Charles F. Westoff, "The potential role of contraception in reducing abortion."

135 John B. Casterline and Steven W. Sinding, "Unmet need for family planning in developing countries and implications for population policy."

*136 Carol E. Kaufman, Thea de Wet, and Jonathan Stadler, "Adolescent pregnancy and parenthood in South Africa."

*137 Valerie L. Durrant and Zeba A. Sathar, "Greater investments in children through women's empowerment: A key to demographic change in Pakistan?"

138 Sajeda Amin, Alaka Malwade Basu, and Rob Stephenson, "Spatial variation in contraceptive use in Bangladesh: Looking beyond the borders."
139 Geoffrey McNicoll, "Managing population-environment systems: Problems of institutional design."

140 Barbara S. Mensch, Barbara L. Ibrahim, Susan M. Lee, and Omaima ElGibaly, "Socialization to gender roles and marriage among Egyptian adolescents."

141 John Bongaarts and Elof Johansson, "Future trends in contraception in the developing world: Prevalence and method mix."

*142 Alaka Malwade Basu and Sajeda Amin, "Some preconditions for fertility decline in Bengal: History, language identity, and an openness to innovations."

143 Zeba Sathar, Cynthia B. Lloyd, Cem Mete, and Minhaj ul Haque, "Schooling opportunities for girls as a stimulus for fertility change in rural $\mathrm{Pa}-$ kistan."

* No longer available 
144 John Bongaarts, "Household size and composition in the developing world."

145 John B. Casterline, Zeba A. Sathar, and Minhaj ul Haque, "Obstacles to contraceptive use in Pakistan: A study in Punjab."

146 Zachary Zimmer, Albert I. Hermalin, and Hui-Sheng Lin, "Whose education counts? The impact of grown children's education on the physical functioning of their parents in Taiwan."

147 Philomena Nyarko, Brian Pence, and Cornelius Debpuur, "Immunization status and child survival in rural Ghana."

*148 John Bongaarts and Zachary Zimmer, "Living arrangements of older adults in the developing world: An analysis of DHS household surveys."

149 Markos Ezra, "Ecological degradation, rural poverty, and migration in Ethiopia: A contextual analysis."
150 Cynthia B. Lloyd, Sahar El Tawila, Wesley H. Clark, and Barbara S. Mensch, "Determinants of educational attainment among adolescents in Egypt: Does school quality make a difference?"

151 Barbara S. Mensch, Paul C. Hewett, and Annabel Erulkar, " The reporting of sensitive behavior among adolescents: A methodological experiment in Kenya."

152 John Bongaarts, "The end of the fertility transition in the developed world."

153 Mark R. Montgomery, GebreEgziabher Kiros, Dominic Agyeman, John B. Casterline, Peter Aglobitse, and Paul Hewett, "Social networks and contraceptive dynamics in southern Ghana."

*154 Paul C. Hewett and Mark R. Montgomery, "Poverty and public services in developing-country cities."

\footnotetext{
* No longer available
} 
155 Zachary Zimmer, Linda G. Martin, and Ming-Cheng Chang, "Changes in functional limitations and survival among the elderly in Taiwan: 1993, 1996, and 1999."

156 John Bongaarts and Griffith Feeney, "How long do we live?"

157 Zachary Zimmer and Sovan Kiry Kim, "Living arrangements and socio-demographic conditions of older adults in Cambodia."

158 Geoffrey McNicoll, "Demographic factors in East Asian regional integration."

159 Carol E. Kaufman, Shelley Clark, Ntsiki Manzini, and Julian May, "How community structures of time and opportunity shape adolescent sexual behavior in South Africa."

160 Julia Dayton and Martha Ainsworth, "The elderly and AIDS: Coping strategies and health consequences in rural Tanzania."

161 John Bongaarts, "The end of the fertility transition in the developing world."
162 Naomi Rutenberg, Carol E. Kaufman, Kate Macintyre, Lisanne Brown, and Ali Karim, "Pregnant or positive: Adolescent childbearing and HIV risk in South Africa."

163 Barbara S. Mensch, Wesley H. Clark, and Dang Nguyen Anh, "Premarital sex in Vietnam: Is the current concern with adolescent reproductive health warranted?"

164 Cynthia B. Lloyd, Cem Mete, and Zeba A. Sathar, "The effect of gender differences in primary school access, type, and quality on the decision to enroll in rural Pakistan."

165 Kelly Hallman, Agnes R. Quisumbing, Marie Ruel, and Bénédicte de la Brière, "Childcare, mothers' work, and earnings: Findings from the urban slums of Guatemala City."

166 Carol E. Kaufman and Stavros E. Stavrou, “'Bus fare, please': The economics of sex and gifts among adolescents in urban South Africa." 